\title{
Sexual Economics, Culture, Men, and Modern Sexual Trends
}

\author{
Roy F. Baumeister • Kathleen D. Vohs
}

Published online: 18 October 2012

(C) Springer Science+Business Media New York 2012

Across the late 20th century, ideas about sex came from two main sources. One was evolutionary theory, based on the field of biology. The other was feminist and social constructionist theory, based in the field of political science. Though important insights have come from both sources, there was a growing body of evidence that did not easily fit either of those. We therefore turned to another field to develop a new theory. The field was economics, and we labeled our theory "sexual economics" (Baumeister and Vohs 2004). At first, our theory was constructed to fit what was already known, making it an exercise in hindsight. It is therefore highly revealing to see how the theory has fared in Regnerus and Uecker's (2011) pioneering studies of the recent, ongoing shifts in sexual behavior in American society.

The value of an economic perspective is abundantly clear in Regnerus's work. Not only does he analyze behavior in terms of markets. In a political democracy, majority rules, and such political principles have often operated in human behavior. But not in sex. In fact, Regnerus shows over and over that when it comes to sex, the minority rules. This is what happens in economics, especially in the dynamics of supply and demand. When supply outnumbers demand, the suppliers (the majority) are in a weak position and must yield ground, such as by reducing their price. In contrast,

\footnotetext{
R. F. Baumeister

The Florida State University,

Tallahassee, FL, USA

K. D. Vohs

Carlson School of Management,

University of Minnesota,

Minneapolis, MN, USA

R. F. Baumeister $(\bowtie)$

Department of Psychology,

1107 W. Call St,

Tallahassee, FL 32306-4301, USA

e-mail: baumeister@psy.fsu.edu
}

when demand outnumbers supply, the suppliers (now the minority) have the advantage and can dictate the terms to their liking, such as by raising the price.

In simple terms, we proposed that in sex, women are the suppliers and men constitute the demand (Baumeister and Vohs 2004). Hence the anti-democratic, seemingly paradoxical sex ratio findings that Regnerus describes. When women are in the minority, the sexual marketplace conforms to their preferences: committed relationships, widespread virginity, faithful partners, and early marriage. For example, American colleges in the 1950s conformed to that pattern. In our analysis, women benefit in such circumstances because the demand for their sexuality exceeds the supply. In contrast, when women are the majority, such as on today's campuses as well as in some ethnic minority communities, things shift toward what men prefer: Plenty of sex without commitment, delayed marriage, extradyadic copulations, and the like.

It is fashionable to describe all gender relations as reflecting the oppression and victimization of women. When women were a minority of students, this was interpreted as indicating that women were victims of oppressive discrimination. Now that women are a majority, they are victims because of not being able to dictate the terms of romantic and sexual behavior. Much of Regnerus's discussion respects this dominant tradition. We also respect that fashion, but as social scientists interested in both genders, we shall use this brief comment to redress the standard imbalance by discussing some implications for men (cf. Baumeister and Vohs 2004).

Sexual marketplaces take the shape they do because nature has biologically built a disadvantage into men: a huge desire for sex that makes men dependent on women. Men's greater desire puts them at a disadvantage, just as when two parties are negotiating a possible sale or deal, the one who is more eager to make the deal is in a weaker position than the one who is willing to walk away without the deal. Women certainly desire sex too - but as long as most women desire 
it less than most men, women have a collective advantage, and social roles and interactions will follow scripts that give women greater power than men (Baumeister et al. 2001). We have even concluded that the cultural suppression of female sexuality throughout much of history and across many different cultures has largely had its roots in the quest for marketplace advantage (see Baumeister and Twenge 2002). Women have often sustained their advantage over men by putting pressure on each other to restrict the supply of sex available to men. As with any monopoly or cartel, restricting the supply leads to a higher price.

It is worth pointing out that the cultural suppression of female sexuality is a particular victory for sexual economics theory. The two dominant theoretical perspectives about sex, evolutionary psychology and feminist/constructionist theory, both strongly predicted the opposite. In a rare agreement between those two, both views proposed that cultures suppress female sexuality to serve male interests, and so male influence has been paramount. Evolutionary theory said that the cultural suppression of female sexuality arose because men wanted to restrain women's sexuality so as to be sure that their partners would be faithful (so the men could be confident of paternity). Feminist theory almost always harks back to male oppression, and so the cultural suppression of female sexuality reflected men's desires to dominate women, possess them, and/or prevent them from finding sexual fulfillment. In both cases, the cultural suppression of female sexuality should come from men. Yet the evidence overwhelmingly indicated that the cultural suppression of female sexuality is propagated and sustained by women (Baumeister and Twenge 2002). Only sexual economics theory predicted that result. Similar to how OPEC seeks to maintain a high price for oil on the world market by restricting the supply, women have often sought to maintain a high price for sex by restricting each other's willingness to supply men with what men want.

Sometimes men have sought to improve their chances for sex by keeping women at a disadvantage in terms of economic, educational, political, and other opportunities (Baumeister and Vohs 2004). For example, researchers have found that in New York in the 1800s, surprisingly high numbers of employed women resorted to occasional prostitution to supplement their meager wages (Elias et al. 1998). But in general this male strategy backfired. Women appear to have realized collectively that sex was the main thing they had to offer men in order to get a piece of society's wealth, and so they restricted sexual access as much as they could, to maintain a high price. Recent work has found that across a large sample of countries today, the economic and political liberation of women is positively correlated with greater availability of sex (Baumeister and Mendoza 2011). Thus, men's access to sex has turned out to be maximized not by keeping women in an economically disadvantaged and dependent condition, but instead by letting them have abundant access and opportunity. In an important sense, the sexual revolution of the 1970s was itself a market correction. Once women had been granted wide opportunities for education and wealth, they no longer had to hold sex hostage (Baumeister and Twenge 2002).

What does all this mean for men? The social trends suggest the continuing influence of a stable fact, namely the strong desire of young men for sexual activity. As the environment has shifted, men have simply adjusted their behavior to find the best means to achieve this same goal. Back in 1960, it was difficult to get sex without getting married or at least engaged, and so men married early. To be sure, this required more than being willing to bend the knee, declare love, and offer a ring. To qualify as marriage material, a man had to have a job or at least a strong prospect of one (such as based on an imminent college degree). The man's overarching goal of getting sex thus motivated him to become a respectable stakeholder contributing to society.

The fact that men became useful members of society as a result of their efforts to obtain sex is not trivial, and it may contain important clues as to the basic relationship between men and culture (see Baumeister 2010). Although this may be considered an unflattering characterization, and it cannot at present be considered a proven fact, we have found no evidence to contradict the basic general principle that men will do whatever is required in order to obtain sex, and perhaps not a great deal more. (One of us characterized this in a previous work as, "If women would stop sleeping with jerks, men would stop being jerks.") If in order to obtain sex men must become pillars of the community, or lie, or amass riches by fair means or foul, or be romantic or funny, then many men will do precisely that. This puts the current sexual free-for-all on today's college campuses in a somewhat less appealing light than it may at first seem. Giving young men easy access to abundant sexual satisfaction deprives society of one of its ways to motivate them to contribute valuable achievements to the culture.

The changes in gender politics since 1960 can be seen as involving a giant trade, in which both genders yielded something of lesser importance to them in order to get something they wanted more (Baumeister and Vohs 2004). As Regnerus states, partly based on our own extensive survey of research findings, men want sex, indeed more than women want it (Baumeister et al. 2001). Women, meanwhile, want not only marriage but also access to careers and preferential treatment in the workplace.

The giant trade thus essentially involved men giving women not only easy access but even preferential treatment in the huge institutions that make up society, which men created. Today most schools, universities, corporations, scientific organizations, governments, and many other institutions have explicit policies to protect and promote women. It 
is standard practice to hire or promote a woman ahead of an equally qualified man. Most large organizations have policies and watchdogs that safeguard women's interests and ensure that women gain preferential treatment over men. Parallel policies or structures to protect men's interests are largely nonexistent and in many cases are explicitly prohibited. Legal scholars, for example, point out that any major new law is carefully scrutinized by feminist legal scholars who quickly criticize any aspect that could be problematic or disadvantageous to women, and so all new laws are women-friendly. Nobody looks out for men, and so the structural changes favoring women and disadvantaging men have accelerated (Baumeister and Vohs 2004).

All of this is a bit ironic, in historical context. The large institutions have almost all been created by men. The notion that women were deliberately oppressed by being excluded from these institutions requires an artful, selective, and motivated way of looking at them. Even today, the women's movement has been a story of women demanding places and preferential treatment in the organizational and institutional structures that men create, rather than women creating organizations and institutions themselves. Almost certainly, this reflects one of the basic motivational differences between men and women, which is that female sociality is focused heavily on one-to-one relationships, whereas male sociality extends to larger groups networks of shallower relationships (e.g., Baumeister and Sommer 1997; Baumeister 2010). Crudely put, women hardly ever create large organizations or social systems. That fact can explain most of the history of gender relations, in which the gender near equality of prehistorical societies was gradually replaced by progressive inequality - not because men banded together to oppress women, but because cultural progress arose from the men's sphere with its large networks of shallow relationships, while the women's sphere remained stagnant because its social structure emphasized intense one-to-one relationships to the near exclusion of all else (see Baumeister 2010). All over the world and throughout history (and prehistory), the contribution of large groups of women to cultural progress has been vanishingly small.

For present purposes, the irony is that men have collectively put themselves at structural disadvantages in the organizations that men have created. (Social scientists like ourselves naturally seek to test hypotheses by considering contrary cases, as in how men fare in large organizations built up by women, but there are too few such organizations to permit general conclusions. The absence of such organizations is an important and revealing fact.) The large social structures that comprise the worlds of business, government and politics, economic relations, science and technological innovation, and the like are male creations, and yet the young men entering any of them are required to accept formal policies that women will be treated preferentially at each step. How can we account for this remarkable, ironic twist of history?

Indeed, the world of work is a daunting place for a young man today. Feminists quickly point to the continued dominance of men at the top of most organizations, but this is misleading if not outright disingenuous. Men create most organizations and work hard to succeed in them. Indeed, an open-minded scholar can search through history mostly in vain to find large organizations created and run by women that have contributed anything beyond complaining about men and demanding a bigger share of the male pie.

Why have men acquiesced so much in giving women the upper hand in society's institutions? It falls to men to create society (because women almost never create large organizations or cultural systems). It seems foolish and selfdefeating for men then to meekly surrender advantageous treatment in all these institutions to women. Moreover, despite many individual exceptions, in general and on average men work harder at their jobs in these institutions than women, thereby enabling men to rise to the top ranks. As a result, women continue to earn less money and have lower status than men, which paradoxically is interpreted to mean that women's preferential treatment should be continued and possibly increased (see review of much evidence in Baumeister 2010). Modern society is not far from embracing explicit policies of "equal pay for less work," as one of us recently proposed. Regardless of that prospect, it appears that preferential treatment of women throughout the workforce is likely to be fairly permanent. Because of women's lesser motivation and ambition, they will likely never equal men in achievement, and their lesser attainment is politically taken as evidence of the need to continue and possibly increase preferential treatment for them.

But this pattern of male behavior makes more sense if we keep in mind that getting sex is a high priority for men, especially young men. Being at a permanent disadvantage in employment and promotion prospects, as a result of affirmative action policies favoring women, is certainly a cost to young men, but perhaps not a highly salient one. What is salient is that sex is quite readily available. As Regnerus reports, even a man with dismal career prospects (e.g., having dropped out of high school) can find a nice assortment of young women to share his bed.

Remember, too, that the ostensible career motivation of many men was infused partly by the desire for sex. That is, one main purpose of work was to make oneself attractive to women as a potential sex partner, including as a husband as long as marriage was the main route to sex. Nowadays young men can skip the wearying detour of getting education and career prospects to qualify for sex. Nor does he have to get married and accept all those costs, including promising to share his lifetime earnings and forego other women forever. Female sex partners are available without all that. 
So maybe the young men don't care that much about how the major social institutions in the world of work have become increasingly rigged to favor women. Sex has become free and easy. This is today's version of the opiate of the (male) masses. The male who beds multiple women is enjoying life quite a bit, and so he may not notice or mind the fact that his educational and occupational advancement is vaguely hampered by all the laws and policies that push women ahead of him. After all, one key reason he wanted that advancement was to get sex, and he already has that. Climbing the corporate ladder for its own sake may still hold some appeal, but undoubtedly it was more compelling when it was vital for obtaining sex. Success isn't as important as it once was, when it was a prerequisite for sex.

If men don't need career success to get sex, then what if anything do they need success for? Some research indicates that career motivation really intensifies for men when they become fathers. Indeed, it has long been known that the transition to parenthood has opposite effects by gender. New mothers withdraw from their work and careers; new fathers embrace work and career with enhanced seriousness and motivation (for a review see Baumeister 1991).

Many of these changes are beyond anyone's control, and so our comments here are not meant to prescribe a radical shift in policies. Still, it is instructive to consider how these changes may affect the future of society.

With regard to work, the societal changes are producing less contribution by men and more by women. These might offset, with few or no costs to society. Still, replacing male with female workers may bring some changes, insofar as the two genders approach work differently. Compared to men, women have higher rates of absenteeism, seek social rewards more than financial ones, are less ambitious, work fewer hours overall, are more prone to take extended career interruptions, and identify less with the organizations they work for. They are more risk averse, resulting in fewer entrepreneurs and inventions. (Baumeister 2010, noted an appalling gender imbalance in new patents; nobody is seriously suggesting that the U.S. Patent office systematically discriminates against women, but women simply do not apply for patents in anything close to the rate that men do.) Women are less interested in science and technology fields. They create less wealth (for themselves and others).

Meanwhile, the implications of the recent social changes for marriage could fill a book. Sexual economics theory has pointed to a wealth of data depicting marriage as a transaction in which the male contributes status and resources while the woman contributes sex (Baumeister and Vohs 2004). How will that play out in the coming decades? The female contribution of sex to the marriage is evanescent: As women age, they lose their sexual appeal much faster than men lose their status and resources, and some alarming evidence even indicates that wives rather quickly lose their desire for sex
(Arndt 2009). To sustain a marriage across multiple decades, many husbands must accommodate to the reality of having to contribute work and other resources to a wife whose contribution of sex dwindles sharply in both quantity and quality - and who also may disapprove sharply of him seeking satisfaction in alternative outlets such as prostitution, pornography, and extramarital dalliance.

We speculate that today's young men may be exceptionally ill prepared for a lifetime of sexual starvation that is the lot of many modern husbands. The traditional view that a wife should sexually satisfy her husband regardless of her own lack of desire has been eroded if not demolished by feminist ideology that has encouraged wives to expect husbands to wait patiently until the wife actually desires sex, with the result that marriage is a prolonged episode of sexual starvation for the husband. (A memorable anecdote from Arndt's 2009 diary study on marital sexuality involved a couple in which the wife refused sex so often that the husband finally said that they would not have sex again until the wife initiated it. When Arndt interviewed them nine years later, he was still waiting.) Today's young men spend their young adulthood having abundant sex with multiple partners, and that seems to us to be an exceptionally poor preparation for a lifetime of sexual starvation.

We do not mean to downplay the struggles and challenges that beset young women (and older women) today. Our focus on men was simply meant as a counterbalance to the Regnerus article that couched its main implications in terms of what current circumstances meant for women. As the originators of sexual economics theory, we seek to adopt the perspective of what is best for the system, not the individuals involved. Throughout history, men and women have needed each other and have managed to create mutually beneficial partnerships (Baumeister 2010). The ground continues to shift, and yet somehow the two genders manage to find each other, have sex, make families, and create another generation. We appreciate Regnerus's various contributions (this issue; 2011) to explain how the ground has shifted and the terms of exchange changed. This comment has sought to elucidate other ways in which social and cultural changes create a new context in which the age-old problems of bringing men and women together must be solved.

Although we have noted warning signs and problems, we remain optimistic. Despite the obstacles and changing contingencies, men and women have always managed to find each other and work together to create a modicum of happiness for both and to create a sphere in which children can grow, thrive, and sustain the culture for another few decades. The coming generation will face novel challenges, but somehow we think they will muddle through and manage to reinvent family life yet again. 


\section{Further Reading}

Arndt, B. 2009. The Sex Diaries: Why Women go off Sex and other Bedroom Battles. Carlton: Melbourne University Press.

Baumeister, R. F. 1991. Meanings of Life. New York: Guilford Press.

Baumeister, R. F. 2010. Is There Anything Good About Men? New York: Oxford University Press.

Baumeister, R. F., \& Mendoza, J. P. 2011. Cultural Variations in the Sexual Marketplace: Gender Equality Correlates with More Sexual Activity. The Journal of Social Psychology, 151, 350-360.

Baumeister, R. F., \& Sommer, K. L. 1997. What Do Men Want? Gender Differences and Two Spheres of Belongingness: Comment on Cross and Madson (1997). Psychological Bulletin, 122, 38-44.

Baumeister, R. F., \& Twenge, J. M. 2002. Cultural Suppression of Female Sexuality. Review of General Psychology, 6, 166-203.

Baumeister, R. F., \& Vohs, K. D. 2004. Sexual economics: Sex As Female Resource for Social Exchange in Heterosexual Interactions. Personality and Social Psychology Review, 8, 339-363.
Baumeister, R. F., Catanese, K. R., \& Vohs, K. D. 2001. Is there a gender difference in strength of sex drive? Theoretical views, conceptual distinctions, and a review of relevant evidence. Personality and Social Psychology Review, 5, 242-273.

Elias, J. E., Bullough, V. L., Elias, V., \& Brewer, G. 1998. Prostitution: On whores, hustlers, and johns. New York: Prometheus.

Regnerus, M., \& Uecker, J. 2011. Premarital Sex in America: How Young Americans Meet, Mate, and Think about Marrying. New York: Oxford University Press.

Roy F. Baumeister is Social Psychology Area Director and Francis Eppes Eminent Scholar at The Florida State University.

Kathleen D. Vohs is Associate Professor, Carlson School of Management and Land O'Lakes Professor of Excellence in Marketing at the University of Minnesota. 